\title{
Preparation of Mn-Modified Tetragonal PZT Ceramics and Their Pyroelectric Properties
}

\author{
Masafumi KOBUNE, Satoshi FUJII and Ken ASADA* \\ Department of Applied Chemistry, Faculty of Engineering, Himeji Institute of Technology, 2167, Shosha, Himeji-shi 671-22 \\ *Faculty of Engineering, Himeji Institute of Technology, 2167, Shosha, Himeji-shi 671-22
}

\author{
マンガンを添加した正方晶 PZT セラミックスの作製とその焦電的性質 \\ 小舟正文・藤井 知・浅田 賢* \\ 姫路工業大学工学部応用化学科, 671-22 姫路市書写 2167 \\ *姫路工業大学工学部, $671-22$ 姫路市書写 2167
}

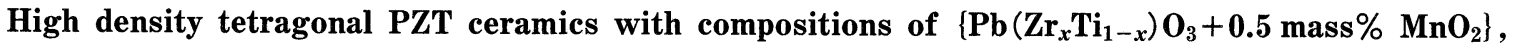
where $\boldsymbol{x}=0.10-0.50$, were synthesized by hot isostatic pressing (HIP). Pressed samples with $\boldsymbol{x}=0.20$ had the highest bulk density of $7.82 \mathrm{~g} / \mathrm{cm}^{3}$, which is $98.2 \%$ of the theoretical density. The pyroelectric properties of poled PZT ceramics with $x=0.10-0.50$ were evaluated. The Curie temperature $T_{\mathrm{C}}$ decreased linearly with increasing $\mathrm{Zr}$ content. The rate of linear decrease $m$ calculated from the slope of the linear plot of $T_{\mathrm{C}}$ with $\boldsymbol{x}$ was approximately $3.0^{\circ} \mathrm{C} / \mathrm{mol} \% \mathrm{Zr}$. The PZT sample with $x=0.20$ exhibited the highest figure of merit F.M. of around $2.1 \times 10^{-11} \mathrm{C} \cdot \mathrm{cm} / \mathrm{J}$. Assuming that the volume specific heat $C_{\mathrm{v}}$ of the present sample with $x=0.20$ and that of $\left\{\mathrm{Pb}\left(\mathrm{Zr}_{x} \mathrm{Ti}_{1-x}\right) \mathrm{O}_{3}+2\right.$ mass $\left.\% \mathrm{ZnBi}_{2 / 3} \mathrm{Mn}_{1 / 3} \mathrm{O}_{3}\right\}$ (PZT-ZBM) ceramic with $x=0.30$ that has already been reported are the same $\left(3.1 \mathrm{~J} / \mathrm{cm}^{3} \cdot \mathrm{K}\right)$, the F.M. for voltage responsivity of pyroelectric IR sensors fabricated using these ceramics which have the same tetragonal structure should be nearly equal.
\end{abstract}

[Received August 24, 1995; Accepted January 18, 1996]

Key-words : PZT, Hot isostatic pressing, Pyroelectric property, Ferroelectrics, Infrared sensor, Relative dielectric constant, Figure of merit

\section{Introduction}

Lead zirconate titanate $\mathrm{Pb}\left(\mathrm{Zr}_{x} \mathrm{Ti}_{1-x}\right) \mathrm{O}_{3}$, (PZT) in which $\mathrm{Zr}^{4+}$ ions are partially substituted at the Bsites $\left(\mathrm{Ti}^{4+}\right.$ ions) in $\mathrm{PbTiO}_{3}$, is an excellent piezoceramic currently used in devices such as ignition elements, piezoelectric speakers and actuators. ${ }^{1)} \mathrm{PZT}$ has a high relative dielectric constant and excellent polarization properties and has been investigated recently as a potential material for small nonvolatile memory elements ${ }^{2}$ which can be used in place of magnetic disks. On the other hand, the pyroelectric properties of PZT ceramics have been investigated by adding small amounts of various additives such as 0.3 mass $\% \mathrm{U}_{3} \mathrm{O}_{8}$ at $x=0.74-0.98,{ }^{3)} 1$ mass $\% \mathrm{Nb}_{2} \mathrm{O}_{5}$ at $x=0.52,{ }^{4)} 2$ mass $\% \mathrm{ZnBi}_{2 / 3} \mathrm{Mn}_{1 / 3} \mathrm{O}_{3}$ at $x=0.30$ $0.70(\mathrm{PZT}-\mathrm{ZBM})^{5)}$ and $0-10 \mathrm{~mol} \% \mathrm{~Pb}(\mathrm{Sn}, \mathrm{Sb}) \mathrm{O}_{3}$ (PZT-PSS) $\left.{ }^{6}\right)$ Thus the many studies on the pyroelectric properties have focused on PZT with a rhombohedral structure $(x \geqq 0.535$; morphotropic phase boundary). In the case of tetragonal PZT ceramics there are few reports on the figure of merit F.M. for voltage responsivity of pyroelectric IR sensors and its variation with $\mathrm{Zr}$ content, except for some on PZT-ZBM $(x=0.30-0.52)$.

In this study, we attempted to synthesize high density tetragonal PZT ceramics with composition $\{\mathrm{Pb}$ $\left(\mathrm{Zr}_{x} \mathrm{Ti}_{1-x}\right) \mathrm{O}_{3}+0.5$ mass $\left.\% \mathrm{MnO}_{2}\right\}$ where $x=0.10$ 0.50 , by hot isostatic pressing (HIP). The pyroelectric properties of these ceramics are compared with those of PZT-ZBM $(x=0.30-0.50)$ ceramics.

\section{Experimental procedures}

\subsection{Sample preparation}

The guaranteed reagents of $\mathrm{PbO}$ (massicot type), $\mathrm{ZrO}_{2}, \mathrm{TiO}_{2}$ (anatase type) and $\mathrm{MnO}_{2}$ additive were used as the starting materials. Powders in proportions appropriate to obtain the composition $\left\{\mathrm{Pb}\left(\mathrm{Zr}_{x}\right.\right.$ $\left.\mathrm{Ti}_{1-x}\right) \mathrm{O}_{3}+0.5$ mass $\left.\% \mathrm{MnO}_{2}, x=0.10-0.50\right\}$ were uniformly mixed and ground for $30 \mathrm{~min}$ in ethanol in an agate mortar. After drying the mixture at $120^{\circ} \mathrm{C}$ for $6 \mathrm{~h}$, it was calcined in a high-purity magnesia crucible of volume $100 \mathrm{~cm}^{3}$ in air at $850^{\circ} \mathrm{C}$ for $1 \mathrm{~h}$. After the calcines were finely pulverized in ethanol in the agate mortar, mixtures in the ratio of $5 \mathrm{~cm}^{3}$ of 1.0 mass\% PVA solution to $10 \mathrm{~g}$ of calcined PZT powders were mixed and ground for around $2 \mathrm{~h}$ in a planetary zirconia wet-ball mill. The wet powders were dried at about $105^{\circ} \mathrm{C}$ for $1.5 \mathrm{~h}$ and then sieved using a 32-mesh screen. The granules obtained were pressed at around $100 \mathrm{MPa}$ into discs $12.7 \mathrm{~mm}$ in diameter and 1-2 mm thick. After the discs were placed in a high-purity $\mathrm{MgO}$ crucible, they were perfectly inlaid with calcined powders having the same composition as the discs. The crucible was placed in a vertical electric furnace and then fired at $1280^{\circ} \mathrm{C}$ for $2 \mathrm{~h}$ in air. Next, the sintered discs were HIPed by the capsule-free method under the following conditions: after the samples prepared by the normal sin- 


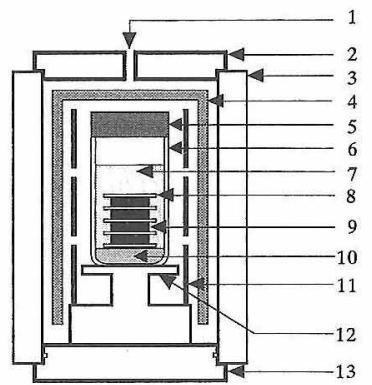

Fig. 1. Schematic diagram of hot isostatic pressing equipment used for synthesizing PZT ceramics.

1: Introducing gate, 2: Upper lid, 3: High-pressure vessel, 4: Adiabatic material, 5: $\mathrm{Al}_{2} \mathrm{O}_{3}$ lid, 6: High-purity $\mathrm{Al}_{2} \mathrm{O}_{3}$ crucible, 7 : PZT powder, 8: Pt leaf, 9: PZT ceramics previously fired at $1280^{\circ} \mathrm{C}$ for 2h, 10: $\mathrm{ZrO}_{2}$ powder, 11: Pt heating element, 12: Support, 13: Lower lid.

tering were set into the HIP equipment indicated in Fig. 1, they were HIPed under mixed gas $\left(\mathrm{Ar} / \mathrm{O}_{2}\right.$ $=80 / 20$ ) pressure of around $100 \mathrm{MPa}$ at $1280^{\circ} \mathrm{C}$ for 1h. The samples obtained were then polished to a thickness of around $0.35 \mathrm{~mm}$. After drying, silver electrodes were attached to their surfaces by firing coated silver paste (SS24386, Nippon Acheson) on the surfaces of the discs at $600^{\circ} \mathrm{C}$ for $30 \mathrm{~min}$ in air.

\subsection{Measurement of physical properties}

The crystalline phase, lattice constant and tetragonality $c / a$ in each sample were analyzed using an X-ray diffractometer (XRD; Rigaku, RINT1500). The lattice constants were determined by applying the least squares method to the X-ray diffraction results obtained using the $111,200,112,211,123$, 312 and 321 reflections of $\mathrm{Cu} \mathrm{K} \alpha$ radiation with highpurity silicon powder (NIST-640b) as the external standard. The apparent porosity and bulk density of each HIPed sample were measured in accordance with the method for magnesia clinker, which is regulated in Gakushin Method-3. The relative density was then obtained by dividing the bulk density by the theoretical density. After a dried sample had been kept in white kerosene for $4 \mathrm{~h}$ at reduced pressure, the physical constants were calculated from the weight of white kerosene absorbed into the sample and that of the dried sample. Additionally, the samples were poled at $150^{\circ} \mathrm{C}$ for $20 \mathrm{~min}$ under a constant d.c. electric field of around $40 \mathrm{kV} / \mathrm{cm}$ in silicone oil (Shin-Etsu Chemical, KF54). The poled samples were measured according to the system for measuring static pyroelectric properties ${ }^{7), 8)}$ which is shown in Fig. 2. The relative dielectric constant $\varepsilon_{\mathrm{r}}$ of samples in the temperature range $30-500^{\circ} \mathrm{C}$ was measured using a multifrequency LCR meter (Yokogawa Hewlett-Packard, 4274A) at $1 \mathrm{kHz}$ under a constant a.c. electric field of $25 \mathrm{~V} / \mathrm{cm}$ (the practical effective value). The resistivity $\rho$ at room temperature was measured by the d.c. three-terminal method using a d.c. voltage source (Yokogawa Hewlett-Packard, $4140 \mathrm{~B})$. The pyroelectric current $i_{\mathrm{p}}$ was measured

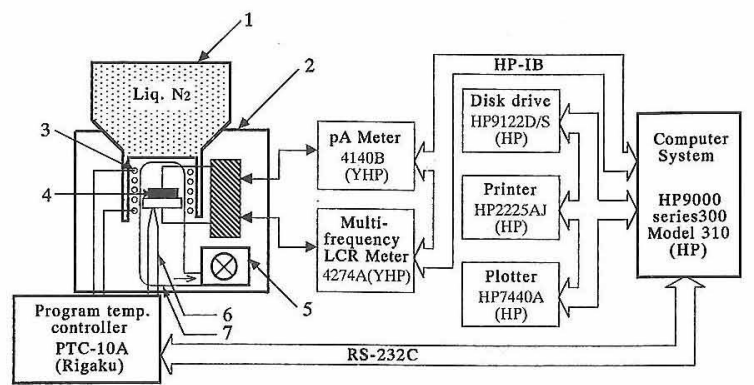

Fig. 2. Schematic diagram for automatic measurement of static pyroelectric properties.

1: Cooling unit, 2: Electric furnace, 3: Heating element, 4: Test piece, 5: Rotary pump, 6: Thermocouple, 7: Quartz tube.

repeatedly using a pA meter (Yokogawa HewlettPackard, 4140B) at a constant rate of temperature change of $1.6^{\circ} \mathrm{C} / \mathrm{min}$ for increasing and decreasing temperature in the range $30-200^{\circ} \mathrm{C}$ in order to eliminate effects due to the induced current. The temperature of the sample was controlled in the range of -30 to $200^{\circ} \mathrm{C}$ under vacuum by a programmed temperature control system, a cooling unit using liquid $\mathrm{N}_{2}(77 \mathrm{~K})$ as a refrigerant and a rotary pump. After measuring $i_{\mathrm{p}}$, the pyroelectric coefficient $P$ was derived from

$$
P=i_{\mathrm{p}} \cdot(\mathrm{d} t / \mathrm{d} T) / S \quad\left(\mathrm{C} / \mathrm{cm}^{2} \cdot \mathrm{K}\right)
$$

where $i_{\mathrm{p}}$ is the pyroelectric current (A), $S$ is the electrode area $\left(\mathrm{cm}^{2}\right), T$ is the absolute temperature $(\mathrm{K})$, $t$ is the time (s) and $\mathrm{d} t / \mathrm{d} T$ is $38.0(\mathrm{~s} / \mathrm{K})$. The figure of merit F.M. for voltage responsivity of a pyroelectric infrared (IR) sensor can be expressed by

$$
\text { F.M. }=P /\left(C_{\mathrm{v}} \cdot \varepsilon_{\mathrm{r}}\right) \quad(\mathrm{C} \cdot \mathrm{cm} / \mathrm{J})
$$

where $C_{\mathrm{v}}$ is the volume specific heat which is $3.1 \mathrm{~J} /$ $\mathrm{cm}^{3} \cdot \mathrm{K} .{ }^{9)}$ The temperature dependence of $\varepsilon_{\mathrm{r}}$ was examined in the $30-500^{\circ} \mathrm{C}$ temperature range. From these results, the Curie temperature $T_{\mathrm{C}}$ was determined from the position of the maximum $\varepsilon_{\mathrm{r}}$. The rate of linear decrease $m$ was calculated from the slope of the linear plot of $T_{\mathrm{C}}$ against $\mathrm{Zr}$ content to evaluate the effects of $\mathrm{Zr}$ added.

\section{Results and discussion}

3.1 Crystalline phase and lattice constant

The X-ray diffraction patterns obtained for $x=0.30 \mathrm{PZT}$ powder calcined at $850^{\circ} \mathrm{C}$ for $1 \mathrm{~h}$ in air, $x=0.30 \mathrm{PZT}$ ceramic fired at $1280^{\circ} \mathrm{C}$ for $2 \mathrm{~h}$ in air and $x=0.30 \mathrm{PZT}$ ceramic HIPed under $100 \mathrm{MPa}$ at $1280^{\circ} \mathrm{C}$ for $1 \mathrm{~h}$ are shown in Figs. $3(\mathrm{a})-(\mathrm{c})$, respectively. The patterns shown in Figs. 3(a) and 3(b) indicate the formation of the PZT phase in this study occurred to obey the reaction mechanism previously reported by Matsuo and Sasaki, ${ }_{10}$ ) that is, after $\mathrm{PbTiO}_{3}$ was formed at the initial low-temperature stage, it reacted chemically with $\mathrm{PbO}$ and $\mathrm{ZrO}_{2}$ at temperatures above $1200^{\circ} \mathrm{C}$, resulting in the formation of the PZT phase. It can be seen from Figs. 3(b) and 3(c) that PZT ceramics both with and without HIP treatment synthesized at $1280^{\circ} \mathrm{C}$ exhibit almost 


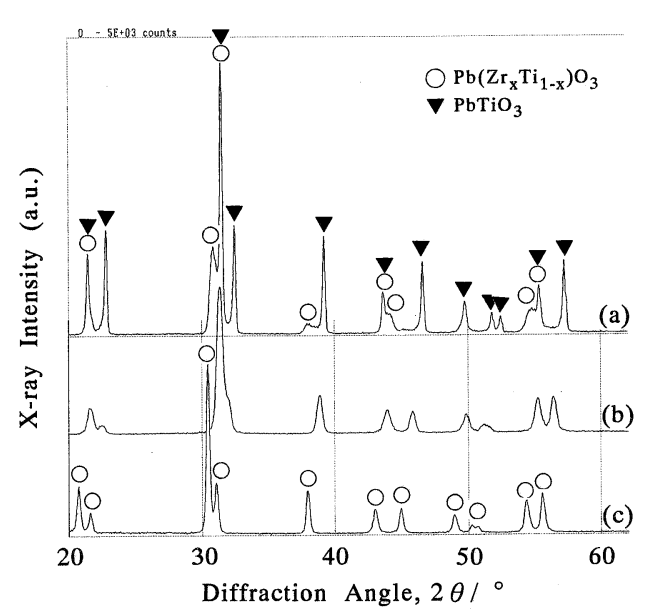

Fig. 3. X-ray diffraction patterns of (a) $x=0.30 \mathrm{PZT}$ powder calcined at $850^{\circ} \mathrm{C}$ for $1 \mathrm{~h}$ in air, (b) $x=0.30 \mathrm{PZT}$ ceramic fired at $1280^{\circ} \mathrm{C}$ for $2 \mathrm{~h}$ in air and (c) $x=0.30 \mathrm{PZT}$ ceramic HIPed under $100 \mathrm{MPa}$ at $1280^{\circ} \mathrm{C}$ for $1 \mathrm{~h}$

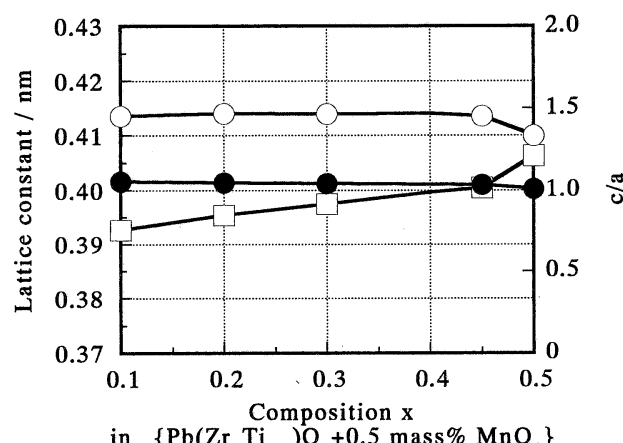

Fig. 4. Lattice constants and tetragonality $c / a$ as a function of the composition $x$.

$\square a, \bigcirc c, \bigcirc c / a$.

single-phase PZT tetragonal structure. The lattice constants and tetragonality $c / a$ for all samples after HIP treatment are shown in Fig. 4. The lattice constants of the PZT samples increase gradually along the $a$-axis but there is little variation along the $c$-axis with increasing $\mathrm{Zr}$ content. The tetragonality $c / a$ of PZT samples with $x=0.10-0.45$ showed a tendency to decrease with increasing $x$. The results obtained are very similar to the lattice constants and tetragonality of PZT ceramics synthesized by the solid-state reaction, which were previously reported by Kakegawa et al. ${ }^{11)}$ The fact that only the value of $a$-axis varies with increasing $x$ may be attributable to fluctuations in the composition.

3.2 Apparent porosity, bulk density and relative density

The apparent porosity, bulk density, theoretical density and relative density for all samples in this study are shown in Table 1. All samples were sintered bodies with low porosity and high bulk density. In particular, samples with $x=0.20$ had the highest bulk density of $7.82 \mathrm{~g} / \mathrm{cm}^{3}$, which is $98.2 \%$ of the theoretical density.
Table 1. Composition $x$, Apparent Porosity, Bulk Density, Theoretical Density and Relative Density of the Synthesized PZT Ceramics

\begin{tabular}{|c|c|c|c|c|}
\hline $\begin{array}{l}\text { Composition } x \\
\text { in } \mathrm{PZT}^{*}\end{array}$ & $\begin{array}{c}\text { Apparent } \\
\text { Porosity } \\
(\%)\end{array}$ & $\begin{array}{c}\text { Bulk } \\
\text { Density } \\
\left(\mathrm{g} \bullet \mathrm{cm}^{-3}\right)\end{array}$ & $\begin{array}{c}\text { Theoretical } \\
\text { Density } \\
\left(\mathrm{g} \bullet \mathrm{cm}^{-3}\right)\end{array}$ & $\begin{array}{c}\text { Relative } \\
\text { Density** } \\
(\%)\end{array}$ \\
\hline 0.10 & 0.04 & 7.75 & 7.97 & 97.2 \\
\hline 0.20 & 0.06 & 7.82 & 7.97 & 98.2 \\
\hline 0.30 & 0.07 & 7.56 & 8.00 & 94.5 \\
\hline 0.40 & 0.12 & 7.69 & 8.02 & 96.0 \\
\hline 0.45 & 0.04 & 7.53 & 8.05 & 93.6 \\
\hline 0.50 & 0.11 & 7.47 & 7.94 & 94.1 \\
\hline
\end{tabular}

\subsection{Pyroelectric properties}

\subsubsection{Relative dielectric constant}

Figure 5 shows the temperature dependence of the relative dielectric constant $\varepsilon_{\mathrm{r}}$ with increasing temperature for three typical samples. The temperature at which $\varepsilon_{\mathrm{r}}$ is a maximum, that is, the Curie temperature $T_{\mathrm{C}}$ apparently shifts toward the lower temperature side with increasing $\mathrm{Zr}$ content. Furthermore, the value of $\varepsilon_{\mathrm{r}}$ at $T_{\mathrm{C}}$ in each sample increased significantly with increasing $\mathrm{Zr}$ content. It can be seen from Fig. 6 that $\varepsilon_{\mathrm{r}}$ at room temperature increases from $196(x=0.10)$ to $861(x=0.50)$ with increasing $\mathrm{Zr}$ content according to the shifting effect of $\mathrm{Zr}$ at the concentration considered in this study. These results nearly agree with the $\varepsilon_{\mathrm{r}}$ values for PZT-ZBM $(x=0.30-0.50)$ ceramics, which were reported by Chechkin et al.5)

\subsubsection{Curie temperature}

Figure 7 shows the Curie temperature $T_{\mathrm{C}}$ as a function of the composition $x$ for PZT-system ceramics with $x=0.10-0.50$. The Curie temperature, determined from the positions of the $\varepsilon_{\mathrm{r}}$ maxima decreases linearly with increasing the $\mathrm{Zr}$ content. The rate of linear decrease $m$ calculated from the linear plot of $T_{\mathrm{C}}$ with $x$ is approximately $3.0^{\circ} \mathrm{C} / \mathrm{mol} \% \mathrm{Zr}$. This result almost coincides with that (approximately $4.0^{\circ} \mathrm{C} / \mathrm{mol} \% \mathrm{Zr}$ ) estimated from previously reported data on PZT-ZBM ceramics with $x=0.30-0.52 .5)$ Based on these results, the $\mathrm{Zr}$ shifting effect on the $\mathrm{PbTiO}_{3}$ was found to be approximately $3.0-4.0^{\circ} \mathrm{C} /$ mol\% $\mathrm{Zr}$ regardless of the sintering agent.

\subsubsection{Pyroelectric coefficient}

The temperature dependence of the pyroelectric coefficient $P$ for three poled samples in the range 30 $200^{\circ} \mathrm{C}$ is shown in Fig. 8. The values of $P$, determined by measuring the actual $i_{\mathrm{p}}$ at various temperatures, vary in proportion to $i_{\mathrm{p}}$ as seen from Eq. (1). $P$ for all samples increased gradually with increasing temperature, and decreased with decreasing temperature. The behavior of $P$ during the heating process for all samples was in good agreement with that during the cooling process within the accuracy of measurement. Therefore, the values of $P$ shown in Fig. 8 are calculated by taking the average of the measured values for increasing and decreasing temperature. The pyroelectric coefficient $P$ at room temperature 


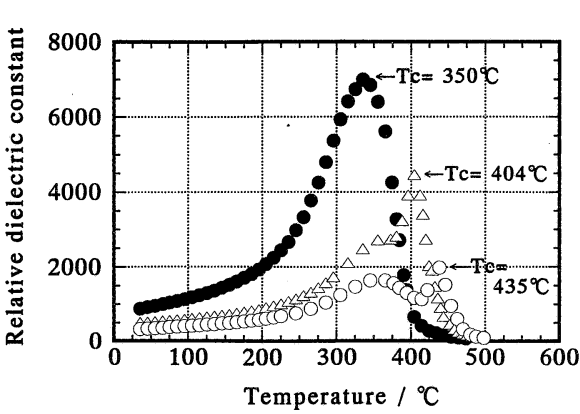

Fig. 5 .

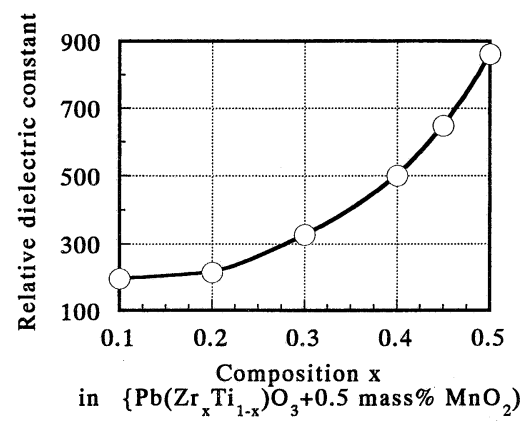

Fig. 6

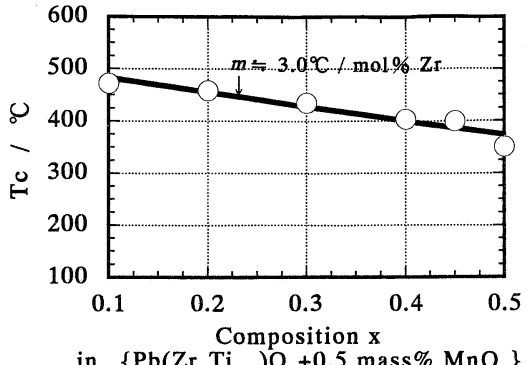

in $\left\{\mathrm{Pb}\left(\mathrm{Zr}_{\mathrm{x}} \mathrm{Ti}_{1-\mathrm{x}}\right) \mathrm{O}_{3}+0.5\right.$ mass $\left.\% \mathrm{MnO}_{2}\right\}$

Fig. 7

Fig. 5. Temperature dependence of relative dielectric constant at increasing temperature for three samples. $\bigcirc x=0.30, \triangle x=0.40, \bigcirc x=0.50$

Fig. 6. Relative dielectric constant at room temperature for all samples as a function of the composition $x$.

Fig. 7. Curie temperature for all samples as a function of the composition $x$.

$m$ : the rate of linear decrease estimated from the slope of the linear plot of $T_{\mathrm{C}}$ with $x$ obtained by the least squares method in the range of $x=0.10-0.50$.

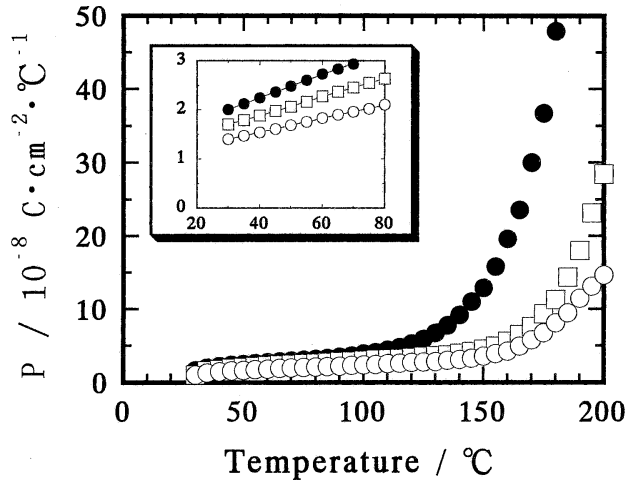

Fig. 8. Temperature dependence of pyroelectric coefficient for three poled samples in the range $30-200^{\circ} \mathrm{C}$.

$\bigcirc x=0.20, \square x=0.30, \bigcirc x=0.45$.

increases slightly with increasing $\mathrm{Zr}$ content, as shown in the insert in Fig. 8. Thus it was proved that an improvement in $P$ at room temperature could be accomplished due to the shifting effect caused by the substitution of $\mathrm{Zr}^{4+}$ ions for $\mathrm{Ti}$ in $\mathrm{PbTiO}_{3}$. The values of $P$ for all samples with $x=0.10-0.50$ were in the range of $0.9-2.0 \times 10^{-8} \mathrm{C} / \mathrm{cm}^{2} \cdot \mathrm{K}$. In contrast, those for PZT-ZBM ceramics with $x=0.30-0.50$ are in the range of $2.0-3.1 \times 10^{-8} \mathrm{C} / \mathrm{cm}^{2} \cdot \mathrm{K},{ }^{5)}$ which is 1.2-1.7 times larger than those of the present samples when samples with the same composition $x$ are compared. It has been reported that tetragonal PZT ceramics modified with $\left.3 \mathrm{~mol} \% \mathrm{~Pb}(\mathrm{Sn}, \mathrm{Sb}) \mathrm{O}_{3}{ }^{6}\right)$ have a large $P\left(\fallingdotseq 1.0-6.0 \times 10^{-8} \mathrm{C} / \mathrm{cm}^{2} \cdot \mathrm{K}\right)$ compared with the above two ceramics. Our results indicate the possibility that larger values of $P$ can be obtained when different plural atoms are incorporated substitutionally into the $\mathrm{Ti}^{4+}$ ion sites in $\mathrm{PbTiO}_{3}$ perovskite structure, adjusting their valence in the B-site.

3.3.4 Figure of merit for pyroelectric IR sensors

A comparison of figures of merit F.M. for the present samples with $x=0.10-0.50$ and PZT-ZBM ceramics with $x=0.30$ is shown in Table 2. The PZT sample with $x=0.20$ exhibited the highest F.M. among the six samples studied here, of around $2.1 \times$ $10^{-11} \mathrm{C} \cdot \mathrm{cm} / \mathrm{J}$. Assuming that the volume specific heat $C_{\mathrm{v}}$ of the present sample with $x=0.20$ and that of PZT-ZBM ceramic with $x=0.30^{5}$ ) are the same

Table 2. Comparison of Figures of Merit for Voltage Responsivity of Pyroelectric IR Sensors Fabricated Using PZT Ceramics and a PZT-ZBM Ceramic with $x=0.30$

\begin{tabular}{|c|c|c|c|c|c|c|c|}
\hline Sample & $\begin{array}{c}\text { Composition } x \\
\text { in PZT }\end{array}$ & $\begin{array}{c}T_{\mathrm{c}} \\
\left({ }^{\circ} \mathrm{C}\right)\end{array}$ & $\varepsilon \mathrm{r}$ & $\begin{array}{c}\rho \\
(\Omega \mathrm{cm})\end{array}$ & $\begin{array}{c}P \\
\left(10^{-8} \mathrm{Ccm}^{-2}{ }^{2} \mathrm{C}^{-1}\right)\end{array}$ & 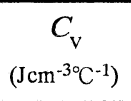 & $\begin{array}{c}\text { F.M. } \\
\left(10^{-11} \mathrm{CcmJ}^{-1}\right)\end{array}$ \\
\hline \multirow[t]{6}{*}{ PZT ceramics ${ }^{*}$} & 0.10 & 472 & 196 & $0.4 \times 10^{11}$ & 0.9 & 3.1 & 1.5 \\
\hline & 0.20 & 458 & 214 & $3.4 \times 10^{11}$ & 1.4 & 3.1 & 2.1 \\
\hline & 0.30 & 435 & 326 & $5.3 \times 10^{11}$ & 1.7 & 3.1 & 1.7 \\
\hline & 0.40 & 404 & 500 & $2.0 \times 10^{11}$ & 1.8 & 3.1 & 1.2 \\
\hline & 0.45 & 400 & 647 & $1.8 \times 10^{11}$ & 2.0 & 3.1 & 1.0 \\
\hline & 0.50 & 350 & 861 & $5.2 \times 10^{11}$ & 1.8 & 3.1 & 0.7 \\
\hline $\begin{array}{l}\text { PZT-ZBM } \\
\text { ceramic }^{* *}\end{array}$ & 0.30 & 430 & 290 & - & 2.0 & - & - \\
\hline
\end{tabular}

* $\mathrm{PZT} ;\left\{\mathrm{Pb}\left(\mathrm{Zr}_{\mathrm{x}} \mathrm{Ti}_{1-\mathrm{x}}\right) \mathrm{O}_{3}+0.5\right.$ mass$\left.\% \mathrm{MnO}_{2}, x=0.10 \sim 0.50\right\}$

** PZT-ZBM ; $\left\{\mathrm{Pb}\left(\mathrm{Zr}_{x} \mathrm{Ti}_{1-\mathrm{x}}\right) \mathrm{O}_{3}+2\right.$ mass $\left.\% \mathrm{ZnBi} 2 / 3 \mathrm{Mn} 1 / 3 \mathrm{O}_{3}\right\}$ 
$\left(3.1 \mathrm{~J} / \mathrm{cm}^{3} \cdot \mathrm{K}\right),{ }^{9)}$ the figures of merit F.M. for voltage responsivity of pyroelectric IR sensors fabricated using these ceramics which have the same tetragonal structure should be nearly equal. Based on these results, it is concluded that PZT ceramics with $x=0.20$ show excellent pyroelectric properties in the tetragonal ( $\mathrm{PZT}+0.5$ mass $\% \mathrm{MnO}_{2}$ ) system.

\section{Summary}

The results of this study are summarized as follows:

(1) High density tetragonal PZT ceramics with compositions of $\left\{\mathrm{Pb}\left(\mathrm{Zr}_{x} \mathrm{Ti}_{1-x}\right) \mathrm{O}_{3}+0.5\right.$ mass\% $\left.\mathrm{MnO}_{2}\right\}$, where $x=0.10-0.50$, were successfully synthesized by hot isostatic pressing.

(2) HIPed samples with $x=0.20$ had the highest bulk density of $7.82 \mathrm{~g} / \mathrm{cm}^{3}$, which is $98.2 \%$ of the theoretical density.

(3) The Curie temperature $T_{\mathrm{C}}$ for PZT ceramics with $x=0.10-0.50$ decreased linearly with an increase in $\mathrm{Zr}$ content. The rate of linear decrease $m$ calculated from the linear plot of $T_{\mathrm{C}}$ with $x$ was approximately $3.0^{\circ} \mathrm{C} / \mathrm{mol} \% \mathrm{Zr}$.

(4) The PZT sample with $x=0.20$ exhibited the highest figure of merit F.M. of around $2.1 \times 10^{-11}$ $\mathrm{C} \cdot \mathrm{cm} / \mathrm{J}$. Assuming that the volume specific heat $C_{\mathrm{v}}$ of the present sample with $x=0.20$ and that of PZTZBM ceramic with $x=0.30$ are the same $\left(3.1 \mathrm{~J} / \mathrm{cm}^{3}\right.$. $\mathrm{K}$ ), the F.M. for voltage responsivity of pyroelectric
IR sensors fabricated using these ceramics which have the same tetragonal structure should be nearly equal.

Acknowledgment This work was supported, in part, by a grant from Izumi Dennetsu K. K., which is gratefully acknowledged.

\section{References}

1) K. Uchino, Electronic Ceramics, 18, No. 3, 9-15 (1987).

2) J. F. Scott, C. A. Araujo and L. D. McMillan, Proceedings of Ultrasonics Symposium (1989) pp. 299-308.

3) R. Lane, D. Luff, K. R. Brown and H. J. Marshallsay, Trans. J. Brit. Ceram. Soc., 72, 39-48 (1973).

4) W. R. Cook, Jr., D. A. Berlincourt and F. J. Scholz, J. Appl. Phys., 34, 1392-98 (1963).

5) V. V. Chechkin, G. E. Savenkova, O. S. Didkovskaya, Yu. N. Venevtsev and V. V. Klimov, Sov. Phys. Tech. Phys., 49, 1397-98 (1979).

6) M. Murata and S. Ito, Proceedings of the 2nd Sensor Symposium (1982) pp. 45-47.

7) R. L. Byer and C. B. Roundy, Ferroelectrics, 3, 333-38 (1972).

8) J. P. Dougherty and R. J. Seymour, Rev. Sci. Instrum., 51, 229-33 (1980).

9) R. Takayama, "Preparation of $\mathrm{PbTiO}_{3}$ System Thin Films and Their Pyroelectric Applications", Doctoral Thesis submitted to Kyoto University (1989) Chap. 5.

10) Y. Matsuo and H. Sasaki, J. Am. Ceram. Soc., 48, 289-91 (1965).

11) K. Kakegawa, K. Watanabe, J. Mohri, H. Yamamura and S. Shirasaki, J. Chem. Soc. Japan, 1975, 413-16 (1975). 